\title{
Tamoxifen induces apoptosis through cancerous inhibitor of protein phosphatase 2A-dependent phospho-Akt inactivation in estrogen receptor- negative human breast cancer cells
}

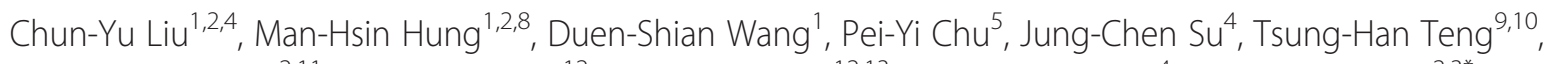
Chun-Teng Huang ${ }^{2,11}$, Ting-Ting Chao ${ }^{12}$, Cheng-Yi Wang ${ }^{12,13}$, Chung-Wai Shiau ${ }^{4}$, Ling-Ming Tseng ${ }^{2,3^{*}}$ and Kuen-Feng Chen ${ }^{6,7^{*}}$

\begin{abstract}
Introduction: Tamoxifen, a selective estrogen receptor (ER) modulator, may affect cancer cell survival through mechanisms other than ER antagonism. In the present study, we tested the efficacy of tamoxifen in a panel of ER-negative breast cancer cell lines and examined the drug mechanism.

Methods: In total, five ER-negative breast cancer cell lines (HCC-1937, MDA-MB-231, MDA-MB-468, MDA-MB-453 and SK-BR-3) were used for in vitro studies. Cellular apoptosis was examined by flow cytometry and Western blot analysis. Signal transduction pathways in cells were assessed by Western blot analysis. The in vivo efficacy of tamoxifen was tested in xenograft nude mice.
\end{abstract}

Results: Tamoxifen induced significant apoptosis in MDA-MB-231, MDA-MB-468, MDA-MB-453 and SK-BR-3 cells, but not in HCC-1937 cells. Tamoxifen-induced apoptosis was associated with inhibition of cancerous inhibitor of protein phosphatase 2A (CIP2A) and phospho-Akt (p-Akt) in a dose-dependent manner. Ectopic expression of either CIP2A or Akt protected MDA-MB-231 cells from tamoxifen-induced apoptosis. In addition, tamoxifen increased protein phosphatase 2A (PP2A) activity, and tamoxifen-induced apoptosis was attenuated by the PP2A antagonist okadaic acid in the sensitive cell lines, but not in resistant HCC-1937 cells. Moreover, silencing CIP2A by small interfering RNA sensitized HCC-1937 cells to tamoxifen-induced apoptosis. Furthermore, tamoxifen regulated CIP2A protein expression by downregulating CIP2A mRNA. Importantly, tamoxifen inhibited the in vivo growth of MDA-MB-468 xenograft tumors in association with CIP2A downregulation, whereas tamoxifen had no significant effect on CIP2A expression and anti-tumor growth in HCC-1937 tumors.

Conclusions: Inhibition of CIP2A determines the effects of tamoxifen-induced apoptosis in ER-negative breast cancer cells. Our data suggest a novel "off-target" mechanism of tamoxifen and suggest that CIP2A/PP2A/p-Akt signaling may be a feasible anti-cancer pathway.

\footnotetext{
* Correspondence: Imtseng@vghtpe.gov.tw; kfchen1970@ntu.edu.tw

${ }^{2}$ School of Medicine, National Yang-Ming University, No. 155, Sec. 2, Li-Nong

Street, Taipei 112, Taiwan

${ }^{6}$ Department of Medical Research, National Taiwan University Hospital, No. 7,

Chung-Shan South Road, Taipei 100, Taiwan

Full list of author information is available at the end of the article
} 


\section{Introduction}

Breast cancer, a major worldwide health threat, is considered to comprise a group of biologically heterogeneous diseases [1-3]. Breast cancer can be classified into different subgroups by the expression of estrogen receptor (ER), progesterone receptor (PR) and human epidermal growth factor receptor 2 (HER2). These subgroups present with distinct molecular backgrounds and exhibit diverse clinical behavior and treatment response $[2,4]$. Among all breast cancers, tumors with negative expression of ER, which accounts for $25 \%$ to $30 \%$ of breast cancer $[4,5]$, is known for its aggressive nature and high metastatic potential [6]. Except for patients with the HER2-amplifying breast cancer subtype, the mainstay treatment for patients with ER-negative breast cancers is chemotherapy $[7,8]$; however, clinical outcomes remain unsatisfactory [2]. Therefore, discovery of novel therapeutic approaches is needed to advance the treatment outcomes of patients with ER-negative breast cancers.

Protein phosphatase 2A (PP2A) has been shown to be an important tumor suppressor protein, and loss of PP2A function has been identified in several malignancies, such as lung, skin, colon, liver and breast cancers [9-11]. PP2A functions as a serine/threonine phosphatase and has been shown to regulate the activity of several oncogenic proteins, such as c-Myc, extracellular signal-regulated kinases and Akt, through direct dephosphorylation, [9,12-14]. In breast cancer, PP2A has been shown to prevent the oncogenic transformation of human breast epithelial cells [13], and, conversely, mutant PP2A was not found to be able to suppress the oncogenic activity of RalA [15]. Recently, an emerging human oncoprotein called cancerous inhibitor of PP2A (CIP2A) has been shown to inhibit PP2A activity [16]. It is overexpressed in many cancers, including breast cancer [17-22]. Importantly, CIP2A overexpression is associated with clinical aggressiveness in human breast cancer and promotes the malignant growth of breast cancer cells [17]. Interestingly, the traditional chemotherapeutic agent doxorubicin has been shown to downregulate CIP2A expression, and increased CIP2A expression confers doxorubicin resistance in breast cancer cells [23]. Moreover, in our recent studies, we found that CIP2A is an important molecular determinant of bortezomib-induced apoptosis in leukemia cells [24] and in breast cancer cells [25]. Together, these data suggest that CIP2A has an important role in breast cancer cells and that targeting CIP2A could be a new therapeutic approach.

Tamoxifen, a selective estrogen-receptor modulator, is an important therapeutic agent for patients with ERpositive breast cancers [26]. The antiestrogenic activity of tamoxifen, by competing with estrogen for binding to the ER in tumor tissue, is considered to be its core mechanism of action, and adjuvant use of tamoxifen after primary resection of ER-positive breast tumor decreases the risk of recurrence [27]. Interestingly, in clinical trials, tamoxifen showed a $10 \%$ to $15 \%$ response rate in tumors without ER expression [26,28]. Moreover, adjuvant tamoxifen treatment after excision of breast ductal carcinoma in situ (DCIS), a form of noninvasive breast carcinoma, has been shown to reduce recurrent risk, even in lesions without ER expression [8]. These clinical findings suggest that tamoxifen has certain ERindependent anticancer properties. Indeed, Blackwell et al. found that tamoxifen could inhibit angiogenesis in an ER-negative fibrosarcoma model [29]. Using the ER-negative HeLa cell model, Obrero et al. found that tamoxifen and its active metabolite could induce mitochondrial dysfunction and subsequently result in apoptotic cell death [30]. Using a virtual screening approach, Rongmin et al. found that 4-hydroxytamoxifen, the active metabolite of tamoxifen, could cause activation of Hsp90 ATPase at micromolar drug concentrations [31]. However, little has been explored regarding the hormone-independent effect of tamoxifen in breast cancer cells.

In this study, we report the apoptotic effect and mechanism of tamoxifen in ER-negative breast cancer cells. We found that downregulation of CIP2A and phosphoAkt (p-Akt) correlated with tamoxifen-induced apoptosis in ER-negative breast cancer cells. Moreover, overexpression of CIP2A or Akt reduced the apoptotic effects in tamoxifen-sensitive cells, whereas silencing CIP2A by small interfering RNA (siRNA) sensitized resistant cells to tamoxifen-induced apoptosis. Importantly, tamoxifen inhibited in vivo xenograft tumor growth in association with CIP2A downregulation. Therefore, tamoxifen induced apoptosis through downregulating CIP2A/PP2A/p-Akt signaling in ER-negative breast cancer cells.

\section{Methods \\ Reagents and antibodies}

Tamoxifen, okadaic acid and forskolin for in vitro experiments were purchased from Cayman Chemical (Ann Arbor, MI, USA). Tamoxifen citrate tablets obtained from AstraZeneca (London, UK) were used for in vivo animal experiments. For in vitro studies, tamoxifen at various concentrations was dissolved in dimethyl sulfoxide (DMSO) and added to cells in Dulbecco's modified Eagle's medium (Invitrogen, Carlsbad, CA, USA). The final DMSO concentration was $0.1 \%$ after addition to the medium. Antibodies for immunoblotting of CIP2A and ER- $\alpha$, Ets1, Elk1 and lamin B were purchased from Santa Cruz Biotechnology (Santa Cruz, CA, USA) for immunoblotting. Other antibodies, such as Akt, p-Akt (Ser473), poly(ADP-ribose) polymerase (PARP) and Myc-tag, were obtained from Cell Signaling Technology (Danvers, MA, USA). 


\section{Cell culture and Western blot analysis}

The HCC-1937, MDA-MB-231, MDA-MB-468, MDAMB-453, SK-BR-3 and MCF-7 cell lines were obtained from American Type Culture Collection (Manassas, VA, USA). All breast cancer cells were maintained in Dulbecco's modified Eagle's medium supplemented with 10\% fetal bovine serum, $0.1 \mathrm{mM}$ nonessential amino acids, $2 \mathrm{mM} \mathrm{L-}$ glutamine, $100 \mathrm{U} / \mathrm{ml}$ penicillin $\mathrm{G}, 100 \mu \mathrm{g} / \mathrm{ml}$ streptomycin sulfate and $25 \mu \mathrm{g} / \mathrm{ml}$ amphotericin $\mathrm{B}$ in a $37^{\circ} \mathrm{C}$ humidified incubator and an atmosphere of $5 \% \mathrm{CO}_{2}$ in air. Lysates of breast cancer cells treated with drugs at the indicated concentrations for various periods of time were prepared for immunoblotting of p-Akt, Akt, CIP $2 A$ and other cells. Western blot analysis was performed as previously reported [25].

\section{Apoptosis analysis}

Drug-induced apoptotic cell death was assessed using measurement of apoptotic cells by flow cytometry (sub-G1 analysis of propidium iodide-stained cells) and Western blot analysis of PARP cleavage.

\section{Gene knockdown using small interfering RNA}

SMARTpool siRNA reagents, including control (D-00181001) and CIP2A, were all purchased from Dharmacon (Lafayette, CO, USA). The experimental procedure we carried out has been cpoibed previously [25]. Briefly, cells were transfected with siRNA (final concentration of $100 \mathrm{nM}$ ) in six-well plates using the liposome transfection reagent Lipofectamine 2000 (Lipo2000; Invitrogen) according to the manufacturer's instructions. After 72 hours, the medium was replaced and the breast cancer cells were incubated with tamoxifen, harvested and separated for Western blot analysis and apoptosis analysis by flow cytometry.

Generation of MDA-MB-231 cells with constitutively active Akt and MDA-MB-231 cells with constitutively active CIP2A CIP2A cDNA (KIAA1524) was purchased from OriGene (RC219918; Rockville, MD, USA) and constructed into a pCMV6 vector. MDA-MB-231 cells were transfected with Myc-tagged Akt1 construct or Myc-tagged CIP2A as previously described [24]. Briefly, following transfection, cells were incubated in the presence of geneticin (G418, $1.40 \mathrm{mg} / \mathrm{ml}$; Invitrogen). After 8 weeks of selection, surviving colonies (that is, those arising from stably transfected cells) were selected and individually amplified.

\section{Protein phosphatase $2 \mathrm{~A}$ activity assay}

The phosphatase activity of PP2A was detected by using a commercial PP2A immunoprecipitation phosphatase assay kit (EMD Millipore, Billerica, MA, USA) according to the manufacturer's instructions and as previously described [24]. In brief, drug-treated or control cells were lysed, and
PP2A was immunoprecipitated with anti-PP2A C subunit antibodies and protein A agarose beads overnight. Protein phosphatase activity of PP2A was determined by measuring the generation of free phosphate from threonine phosphopeptide using the malachite green phosphate complex assay. To avoid variability due to differences in the amounts of immunoprecipitated protein between samples, the phosphatase activities were normalized to the amount of PP2A immunoprecipitated, as detected and quantified by immunoblot analysis for each treatment group.

\section{Luciferase reporter constructs for the CIP2A promoter and $5^{\prime}$ detection analysis}

The upstream region of the CIP2A promoter containing exon 1 ( $-2,000$ bp to $-1 \mathrm{bp})$ was amplified by PCR from the genomic DNA of cells and cloned into the reporter vector, Firefly vector (pGL4.17; Promega, Madison, WI, USA) by KpnI and BglII restriction sites. PCR-amplified promoter regions $-2,000 /-1,-400 /-1,-110 /-1$ and $-62 /-1$ were cloned into the KpnI and BglII restriction sites of the pGL4 basic vector. The nucleotide sequence of the clones was verified by sequencing.

\section{Dual-luciferase reporter assay}

The promoter activity of CIP2A was determined using the dual-luciferase reporter assay kit (Promega) according to the manufacturer's instructions. MDA-MB-468 cells were cotransfected with the luciferase reporter constructs pGL4.17-CIP2A-promoter (Firefly fluorescence reporter) and PGL4.74-Renilla (Renilla fluorescence reporter) as indicators for normalization of transfection efficiency. Twenty-four hours posttransfection, cells were treated with tamoxifen $(5 \mu \mathrm{M})$ or DMSO for 24 hours. Cells were then lysed and assayed for luciferase activity. The promoter activity was repeated three times in parallel for statistical analysis.

\section{Chromatin immunoprecipitation assay}

Chromatin immunoprecipitation (ChIP) was performed using the Pierce Agarose ChIP Kit (Pierce Biotechnology/ Thermo Fisher Scientific, Rockford, IL, USA) according to the manufacturer's instructions. Briefly, $1 \times 10^{7} \mathrm{MDA}$ MB-468 cells were treated with tamoxifen $7.5 \mu \mathrm{M}$ or DMSO for 24 hours. Physical cross-linking between chromatin (DNA) and proteins was fixed by $1 \%$ formaldehyde at room temperature for 10 minutes. Next, cells were lysed for DNA by enzyme digestion (micrococcal nuclease, $37^{\circ} \mathrm{C}, 15$ minutes), and phosphatase inhibitor and protease inhibitor were added in the cell lysis step to avoid protein degradation. Lysates were clarified by centrifugation at $12,500 \times g$ for 5 minutes at $4{ }^{\circ} \mathrm{C}$. Immunoprecipitation was performed by adding Elk1, Ets1 or rabbit immunoglobulin $\mathrm{G}$ antibodies as the negative control. The immunocomplex was precipitated by incubation 
with $25 \mu$ l of protein $\mathrm{A} / \mathrm{G}$ magnetic beads for 1 hour at $4^{\circ} \mathrm{C}$. The protein-DNA complex was eluted using $200 \mu \mathrm{l}$ of elution buffer from the beads. Cross-linking of proteinDNA was reversed by adding $8 \mu \mathrm{l}$ of $5 \mathrm{M} \mathrm{NaCl}$ at $95^{\circ} \mathrm{C}$ for 15 minutes. The DNA was purified using spin columns, and $2 \mu \mathrm{l}$ of the DNA was used in the semi-PCR for amplification of the CIP2A promoter region (-139/-16 bp). Anti-RNA polymerase II antibody and glyceraldehyde 3 -phosphate dehydrogenase (GAPDH) primers were provided by the manufacturer as a positive control for the assay technique and reagent integrity.

\section{Xenograft tumor growth}

The animal study was approved by the Institutional Animal Care and Use Committee of Taipei Veterans General Hospital. All experimental procedures using these mice were performed in accordance with protocols approved by the Institutional Animal Care and Use Committee of Taipei Veterans General Hospital. Male NCr athymic nude mice (5 to 7 weeks of age) were obtained from the National Laboratory Animal Center (Taipei, Taiwan, Republic of China). The mice were housed in groups and maintained in a specific pathogen-free environment. Each mouse was inoculated subcutaneously in the dorsal flank while under isoflurane anesthesia with $5 \times 10^{6}$ breast cancer cells suspended in $0.1 \mathrm{ml}$ of serum-free medium containing $50 \%$ Matrigel (BD Biosciences, San Jose, CA, USA). Tumors were measured using calipers, and their volumes were calculated using a standard formula: Width ${ }^{2} \times$ Length $\times 0.52$. When tumors reached around $200 \mathrm{~mm}^{3}$, mice were orally administered $100 \mathrm{mg} / \mathrm{kg}$ body weight tamoxifen citrate three times weekly for 4 to 5 weeks. Controls received vehicle ( $1 \times$ phosphate-buffered saline). Mice were killed upon termination of treatment, and xenografted tumors were harvested and assayed for molecular events by Western blot analysis.

\section{RT-PCR}

Total RNA was extracted from cultured cells using TRIzol reagent (Invitrogen), and RT-PCR was performed according to the manufacturer's instructions (MBI Fermentas, Vilnius, Lithuania). RT-PCR analyses were performed as previously described [25] with specific primers for human CIP2A (forward primer, 5' -TGGCAAGATTGACCTGGGATT TGGA-3'; reverse primer, 5'-AGGAGTAATCAAAC GvTGGGTCCTGA-3'; $172 \mathrm{bp}$ ), and the GAPDH gene was chosen as an internal control (forward primer, 5' -CGACCACTTTGTCAAGCTCA-3'; reverse primer, 5'-AGGGGTCTACAT GGCAACTG-3'; 228 bp). qRTPCR was performed in a LightCycler 480 Instrument II (Roche Diagnostics, Indianapolis, IN, USA) using a LightCycler 480 SYBR Green I Master kit (Roche Diagnostics). The primers were the same as those above described.

\section{Immunohistochemical staining}

Paraffin-embedded breast cancer tissue sections $(4 \mu \mathrm{m})$ on poly-L-lysine-coated slides were deparaffinized and rinsed with $10 \mathrm{mM}$ Tris- $\mathrm{HCl}(\mathrm{pH}$ 7.4) and $150 \mathrm{mM}$ sodium chloride. Peroxidase was quenched with methanol and $3 \%$ hydrogen peroxide. Slides were then placed in $10 \mathrm{mM}$ citrate buffer $(\mathrm{pH} 6.0)$ at $100^{\circ} \mathrm{C}$ for 20 minutes in a pressurized heating chamber. After incubation with a 1:200 dilution of p-Akt1/2/3 (Thr 308)-R antibody (sc-16646-R; Santa Cruz Biotechnology) and with a 1:100 dilution of CIP2A antibody (ab84547; Abcam, Cambridge, UK) for 1 hour at room temperature, slides were thoroughly washed three times with phosphate-buffered saline. Bound antibodies were detected using the EnVision Detection Systems Peroxidase/DAB, Rabbit/Mouse kit (Dako, Glostrup, Denmark). The slides were then counterstained with hematoxylin. Paraffin-embedded sections of mouse kidney tissue and human colon carcinoma were used as positive controls for $\mathrm{p}$-Akt1/2/3 and CIP2A, respectively, as described in the datasheet from the manufacturer. Negative controls had the primary antibody replaced by phosphate-buffered saline. A board-certified pathologist assessed the expression of $\mathrm{p}-\mathrm{Akt} 1 / 2 / 3$ and CIP2A semiquantitatively based on the intensity of staining. The intensity of staining was scored as negative, weak, moderate and strong staining.

This study was approved by the ethics committee of the Institutional Review Board of Taipei Veterans General Hospital. All informed consents from sample donors were in accordance with the Declaration of Helsinki and were obtained at the time of donation.

\section{Statistical analysis}

Data are expressed as mean \pm SD or SE. Statistical comparisons were based on nonparametric tests, and statistical significance was defined as $P<0.05$. For survival analysis, progression-free survival curves of patients were generated using the Kaplan-Meier method and compared by performing a logrank test. All statistical analyses were carried out using SPSS for Windows software, version 12.0 (SPSS, Chicago, IL, USA).

\section{Results}

\section{Differential apoptotic effects of tamoxifen on estrogen} receptor-negative breast cancer cells

To understand the antitumor effect of tamoxifen on ER-negative breast cancer cells, we first assessed its apoptotic effect in a panel of five ER-negative human breast cancer cell lines: SK-BR3, MDA-MB-453, MDAMB-468, MDA-MB-231 and HCC-1937. First, negative expression of ER in the cell lines was confirmed by Western blotting (Figure 1A). Flow cytometric analysis of sub- $G_{1}$ cells showed that tamoxifen induced differential apoptotic effects at the indicated times ( 24 and 36 hours) 


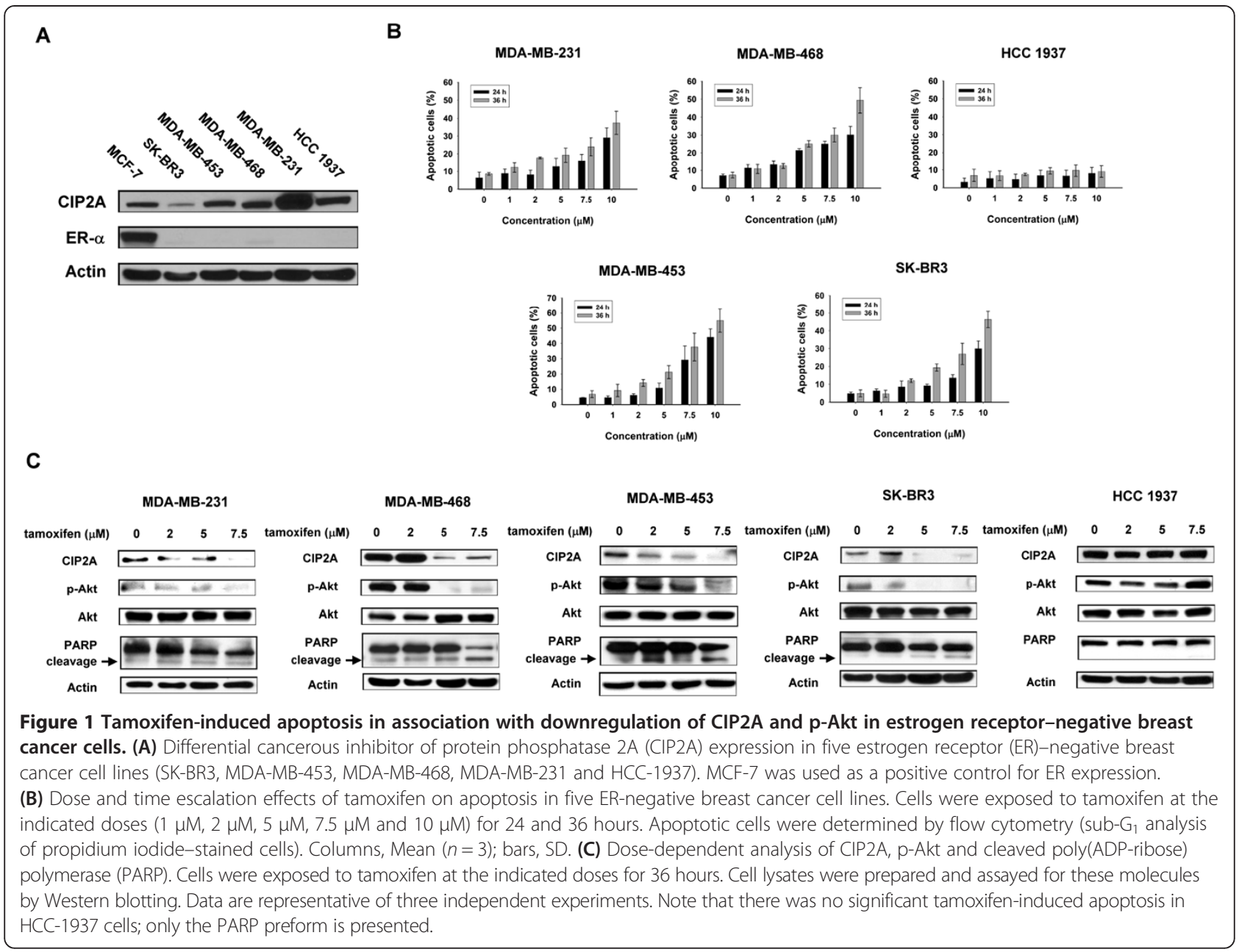

and doses $(1,2,5,7.5$ and $10 \mu \mathrm{M})$ in the five breast cancer cell lines (Figure 1B). Tamoxifen induced apoptosis in a dose- and time-dependent manner in MDA-MB-231, MDA-MB-468, MDA-MB-453 and SK-BR3 cells, whereas no apparent apoptotic effects were observed in HCC-1937 cells after tamoxifen treatment for 24 and 36 hours at doses up to $10 \mu \mathrm{M}$ (Figure 1B). These results suggest that ER-negative breast cancer cell lines MDA-MB-231, MDAMB-468, MDA-MB-453 and SK-BR3 cells are sensitive to the cytotoxic effect of tamoxifen, but that the HCC-1937 cell line is not.

Tamoxifen induces apoptosis in association with downregulation of CIP2A and p-Akt in sensitive estrogen receptor-negative breast cancer cells

We previously found that bortezomib induced apoptosis in triple-negative (negative expression of ER, PR and HER2) breast cancer cells through downregulation of CIP2A and p-Akt, suggesting that CIP2A is a target of bortezomib [25]. In this study, we investigated the molecular events associated with apoptosis induced by tamoxifen in ER-negative breast cancer cells, with a particular focus on CIP2A. As revealed in Figure 1C, in the four tamoxifen-sensitive cell lines MDA-MB-231, MDA-MB-468, MDA-MB-453 and SK-BR3, the protein levels of CIP2A were downregulated by tamoxifen in a dose-dependent manner. Moreover, inhibition of CIP2A was associated with downregulation of p-Akt and induction of apoptosis (evident by increased cleavage of PARP). In contrast, the protein levels of CIP2A, p-Akt and PARP were not significantly affected by tamoxifen in HCC-1937 cells. The results suggest that inhibition of CIP2A may play a major role in tamoxifen-induced apoptosis in ER-negative breast cancer cells. We also tested the effects of tamoxifen on CIP2A and p-Akt in ER-positive MCF-7 cells (Additional file 1: Figure S1). As shown in Additional file 1: Figure S1, tamoxifen also induced apoptosis in association with CIP2A and p-Akt downregulation in MCF-7 cells.

Tamoxifen has a well-established ER $\alpha$-selective partial agonist/antagonist function and can induce apoptotic as well as antiproliferative effects, which raises the issue 
whether ER $\alpha$ plays a distinct role in tamoxifen-induced effects on CIP2A, p-Akt and apoptosis. In this regard, we used fulvestrant (formerly ICI 182,780), a structural analogue of estrogen with a pure antagonist function on $E R \alpha$, and tested the effects of fulvestrant in ER $\alpha$-positive MCF-7 cells and ER $\alpha$-negative MDA-MB-453 cells. To show the effect of fulvestrant on apoptosis in both ER $\alpha$ positive cells and ER $\alpha$-negative cells, we used a relative higher dose $(1 \mu \mathrm{M})$ than the normally used doses (around $100 \mathrm{nM}$ ) for in vitro studies of ER $\alpha$-positive cells [32]. As expected, both tamoxifen and fulvestrant could downregulate ER $\alpha$ in MCF-7 cells, a known effect contributing to apoptosis (Additional file 1: Figure S2). In addition, the CIP2A downregulation seemed more prominent in MDA-MB-453 cells than in MCF-7 cells; however, tamoxifen-induced apoptosis seemed higher in MCF-7 cells. Together our data show an "off-ER $\alpha$ " effect of tamoxifen. Because a second estrogen receptor, ER $\beta$, has been found to be expressed in $50 \%$ to $90 \%$ of $E R \alpha-$ negative breast cancers [33], we also checked the expression of ER $\beta$ in MCF-7 cells and ER $\alpha$-negative cells and found that these cells also showed positive ER $\beta$ expression (Additional file 1: Figure S3).

\section{Target validation of the CIP2A/PP2A/p-Akt pathway as a molecular determinant of tamoxifen-induced estrogen receptor-negative breast cancer apoptosis}

To examine the role of CIP2A and p-Akt in mediating tamoxifen-induced apoptosis, we generated MDA-MB231 cells with constitutive, ectopic expression of Myctagged Akt (Figure 2A) or Myc-tagged CIP2A (Figure 2B). Of note, MDA-MB-231 cells with constitutive, ectopic expression of Myc-tagged Akt also expressed constitutively activated p-Akt (Figure 2A). As shown in Figures 2A and $2 \mathrm{~B}$, constitutive ectopic expression of either Myctagged Akt or CIP2A protected sensitive MDA-MB-231 cells from apoptotic death induced by tamoxifen. Because CIP2A is a cellular inhibitor of PP2A [16,24], we examined the PP2A activity in tamoxifen-treated cells. As shown in Figure 2C, tamoxifen significantly increased the phosphatase activity of PP2A in tamoxifen-sensitive cell lines (Figure 2C). In addition, okadaic acid, a PP2A inhibitor acting as a negative control, decreased the phosphatase activity of PP2A in these four cell lines; however, forskolin, a PP2A agonist acting as a positive control, increased PP2A activity in these cells (Figure 2C). Moreover, pretreatment with okadaic acid reduced the effects of tamoxifen on apoptosis and p-Akt in tamoxifen-sensitive MDA-MB-231, MDA-MB-468 and MDA-MB-453 cells (Figure 2D), whereas cotreatment with forskolin sensitized HCC-1937 cells to tamoxifen-induced apoptosis and pAkt downregulation (Figure 2E). We also checked PP2A activity in these cells (Additional file 1: Figure S4). As shown in the Additional file 1: Figure S4, forskolin increased PP2A activity in HCC-1937 cells, and the combination of tamoxifen and forskolin further increased PP2A activity. Next, we performed knockdown of expression of CIP2A by using siRNA and found that CIP2A siRNA sensitized the resistant HCC-1937 cells to tamoxifen-induced apoptosis (Figure 2F). Notably, depletion of CIP2A alone did not induce significant apoptosis in tamoxifen-resistant HCC-1937 cells (Figure 2F); therefore, we further examined whether CIP2A siRNA alone induced apoptosis in the tamoxifen-sensitive MDAMB-468 cells (Additional file 1: Figure S5). Similarly, CIP2A siRNA alone did not induce significant apoptosis. However, tamoxifen plus CIP2A siRNA induced significantly more apoptosis as compared to tamoxifen treatment (Additional file 1: Figure S5). It can be argued that CIP2A downregulation per se may also participate in the apoptosis mechanism. In this regard, we further tested the effects of common chemotherapeutic agents for breast cancers, including 5-fluorouracil (5-FU), paclitaxel and docetaxel, and compared them with tamoxifen in MDAMB-468 cells (Additional file 1: Figure S6). We found that only tamoxifen induced significant CIP2A reduction, whereas all of these agents induced apoptosis in MDAMB-468 cells. Together, these results indicate that the CIP2A/PP2A/p-Akt pathway plays a critical role in mediating the apoptotic effect of tamoxifen in ER-negative breast cancer cells.

Researchers in some studies have proposed other ERindependent therapeutic potential of tamoxifen, such as activation of Hsp90 [31]. Therefore, we performed coimmunoprecipitation experiments with CIP2A and Hsp90 in tamoxifen-treated MDA-MB-468 cells, and we found no apparent interactions between these two molecules upon tamoxifen treatment (Additional file 1: Figure S7). In addition, because PP2A comprises a large family of protein phosphatases known to affect apoptosis by regulating multiple pro- or antiapoptotic proteins, such as c-Myc and $\mathrm{Bcl}-2$ [12]. It is possible that tamoxifen-induced CIP2A inhibition could also affect cell survival through dysregulation of PP2A substrates involved in apoptosis. Accordingly, we checked the effects of tamoxifen on cMyc and Bcl-2 in tamoxifen-sensitive cells. Tamoxifen showed differential effects on $\mathrm{c}-\mathrm{Myc}$ and $\mathrm{Bcl}-2$ in sensitive cell lines (MDA-MB-468, MDA-MB-231, MDA-MD-453 and SK-BR3); it reduced c-Myc expression more prominently in SK-BR3 cells; and it reduced Bcl-2 expression more prominently in MDA-MB-231 cells (Additional file 1: Figure S8).

\section{Tamoxifen downregulates transcription of CIP2A in estrogen receptor-negative breast cancer cells}

To further study how tamoxifen affected CIP2A expression, we first examined whether tamoxifen could affect CIP2A elimination (degradation) when translation was blocked 

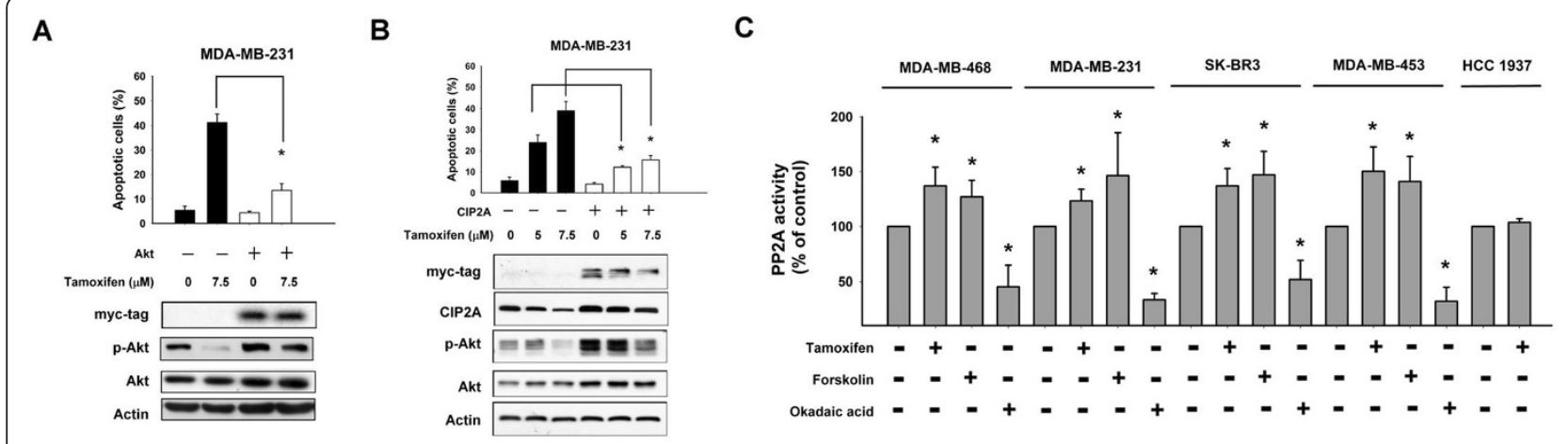

D
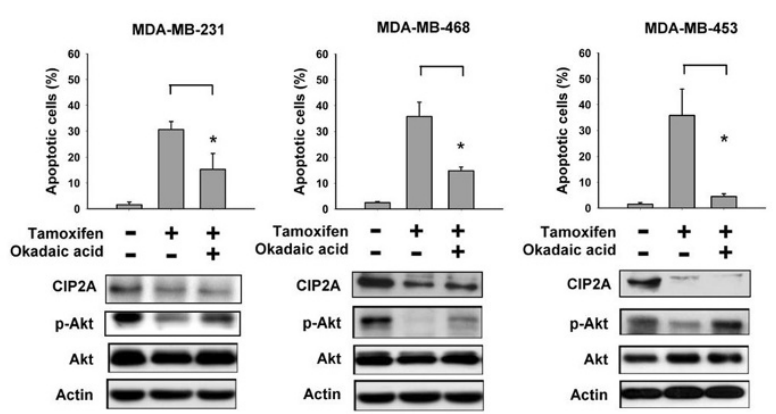

E
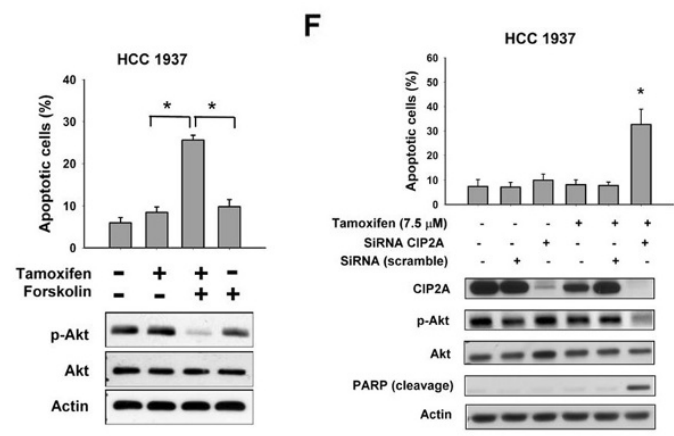

Figure 2 CIP2A/PP2A/p-Akt mediated tamoxifen-induced apoptosis. (A) Ectopicexpression of myc-tagged Akt protected MDA-MB-231 cells from tamoxifen-induced apoptosis. (B) Ectopic expression of myc-tagged CIP2A protected MDA-MB-231cells from tamoxifen-induced apoptosis. Note that cells with ectopic expression of myc-tagged CIP2A also had constitutively high p-Akt. For experiments (A) and (B), cells were transfected as described in Material and Methods. Control cells were empty-vector cells. Apoptosis was analyzed by flow cytometry after cells were sequentially exposed to DMSO or tamoxifen at the indicated doses for 36 hours. (C) Analysis of PP2A activity in drug-treated cells. Cells were treated with DMSO ortamoxifen at $7.5 \mu \mathrm{M}$ or okadaic acid at $20 \mathrm{nM}$ (as a negative control) or forskolin 40 $\mu \mathrm{M}$ (as a positive control) for 36 hours. Cell lysates were assayed for PP2A activity. (D) Pretreatment of PP2A inhibitor okadaic acid protected cells from tamoxifen-induced apoptosis. Cells were treated with DMSO (control) or tamoxifen $(7.5 \mu \mathrm{M})$ for 36 hours. For pretreatment, cells were pretreated with okadaic acid (20nM) for 1 hour; then they were washed and treated with tamoxifen $(7.5 \mu \mathrm{M})$ for 36 hours. Cell lysates were separated and assayed for sub-G1 analysis and westernblotting. (E) Cotreatment of tamoxifen with forskolin enhanced apoptosis in resistant HCC-1937 cells. Cells were treated with DMSO (control), tamoxifen $(7.5 \mu \mathrm{M})$, or co-treated with tamoxifen $(7.5 \mu \mathrm{M})$ and forskolin $(40 \mu \mathrm{M})$ for 36 hours. Cell lysates were separated and assayed for sub-G1 analysis and western blotting. (F) Downregulation of CIP2A by siRNA increased tamoxifen-induced apoptosis in HCC-1937 cells. Cells were transfected with either control (scrambled siRNA) or CIP2A siRNA for 72 hours followed by exposure to tamoxifen at $7.5 \mu \mathrm{M}$ for 36 hours. For $(\mathbf{A})$ to $(\mathbf{F})$, Columns, mean $(n=3)$; bars, $S D ;{ }^{*} P<0.05$.

by the protein synthesis inhibitor cycloheximide. Our data showed that after protein translation was blocked by cycloheximide, the rate of CIP2A degradation did not change significantly with or without tamoxifen treatment in MDA-MB-231 and MDA-MB-468 cells (Figure 3A). This implies that the effect of tamoxifen on CIP2A may occur at the pretranslation level. We next investigated whether tamoxifen affected CIP2A transcription via quantitative RT-PCR analysis. As shown in Figure 3B, CIP2A mRNA levels decreased in a dose-dependent manner upon treatment with tamoxifen in sensitive MDA-MB231, MDA-MB-468 and MDA-MB-453 cells, but not in resistant HCC-1937 cells (Figure 3B). These results indicate that tamoxifen inhibited CIP2A transcription, and failure of this inhibition suggests tamoxifen resistance in ER-negative breast cancer cells.
To further decipher the possible mechanism how tamoxifen reduced CIP2A mRNA, we presumed that tamoxifen may affect CIP2A promoter activity through transcription factors because researchers in previous studies have unraveled several transcriptional regulators of CIP2A promoter [34,35]. Accordingly, MDA-MB-468 cells were transfected with luciferase reporter constructs for CIP2A promoter of varying lengths (Figure 3C). As shown in Figure 3C, tamoxifen significantly downregulated the activity of CIP2A promoter in cells transfected with constructs of -1 to approximately $-2,000 \mathrm{bp}$ and -1 to about $-400 \mathrm{bp}$, but tamoxifen did not reduce CIP2A promoter activity in cells transfected with constructs of -1 to approximately -110 and -1 to about $-62 \mathrm{bp}$. According to previous studies [34,35], Ets1 and Elk1 could bind to promoter regions between -400 and $-110 \mathrm{bp}$. Next, we 


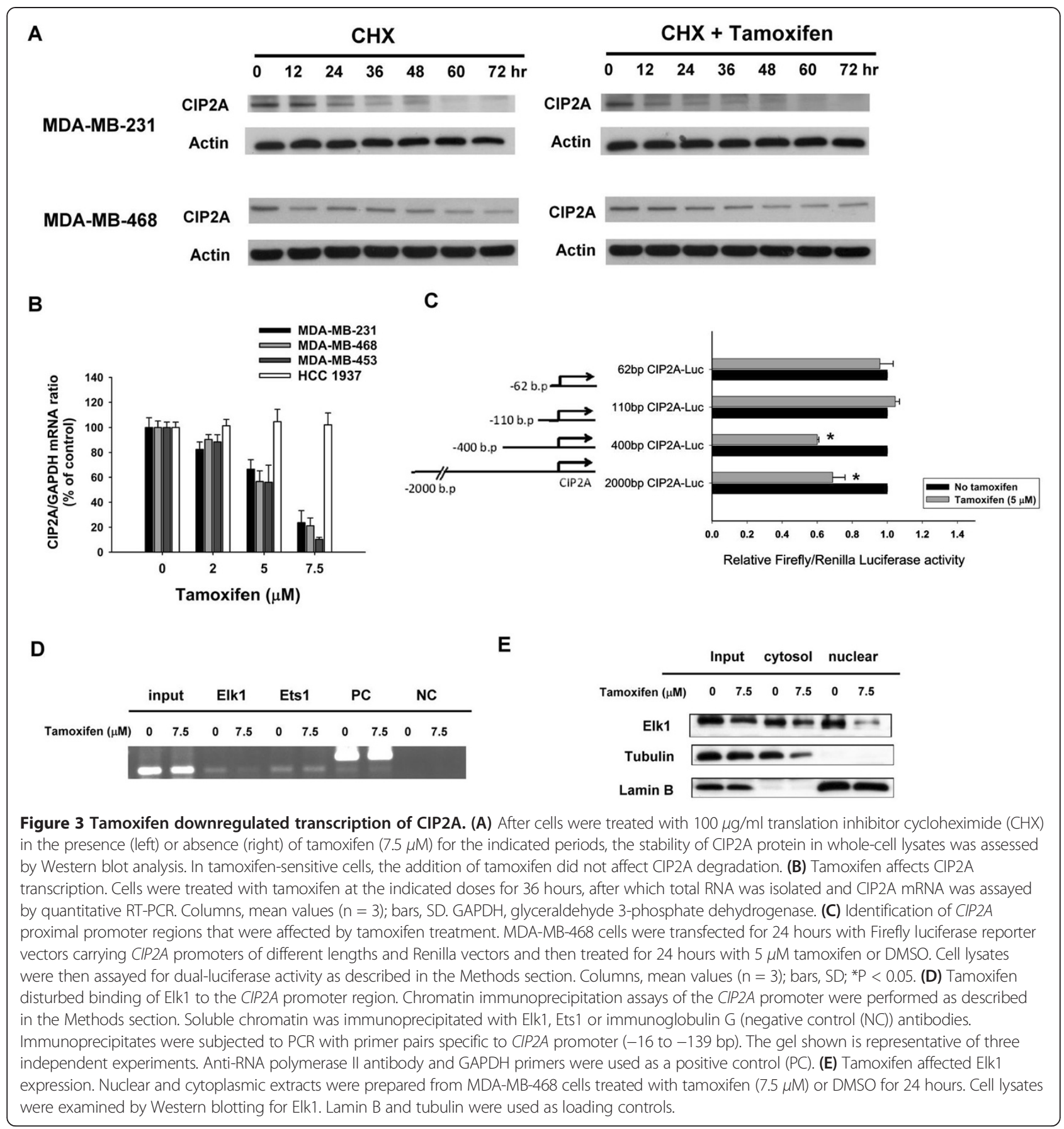

performed ChIP assays (Figure 3D) to examine whether the binding of Ets1 or Elk1 (or both) to CIP2A promoter is affected by tamoxifen. We found that tamoxifen disturbed the binding of Elk1 to CIP2A promoter. Further Western blot analysis for Elk1 in nuclear/cytoplasmic extracts from MDA-MB-468 cells treated with or without tamoxifen revealed that tamoxifen reduced Elk1 expression in the nuclear extracts (Figure 3D). These data suggest that tamoxifen may downregulate CIP2A transcription by affecting Elk1.
Effect of tamoxifen on estrogen receptor-negative breast cancer xenograft tumor growth in vivo

To confirm that using tamoxifen to inhibit CIP2A has potentially clinically relevant implications in ER-negative breast cancer, we next used ER-negative breast cancer xenograft models to evaluate the effect of tamoxifen in vivo. Mice with MDA-MB-468- and HCC-1937xenografted tumors were generated to validate the role of CIP2A in vivo. After successfully establishing the xenograft model in nude mice, these tumor-bearing mice 
were treated with tamoxifen at the dose of $100 \mathrm{mg} / \mathrm{kg}$ or vehicle (as control) orally three times per week for 4 to 5 weeks. As shown in Figure 4A, tamoxifen inhibited MDA-MB-468 tumor growth significantly, whereas HCC1937 tumor growth was not affected. Furthermore, the protein expression of CIP2A, p-Akt and Akt were checked to confirm the correlation between the biological response observed in vivo and the molecular mechanism discovered in vitro (Figure $4 \mathrm{~B}$ ). Tamoxifen inhibited the expression of CIP2A and p-Akt consistently in the three representative

A

MDA-MB-468 tumors

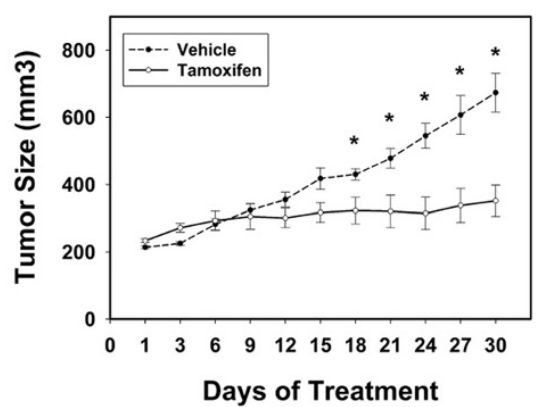

B

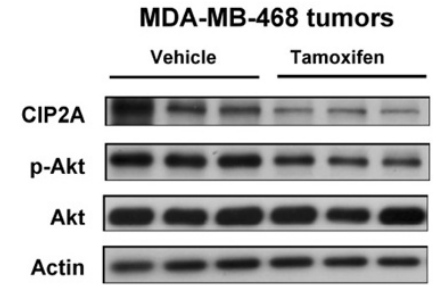

C
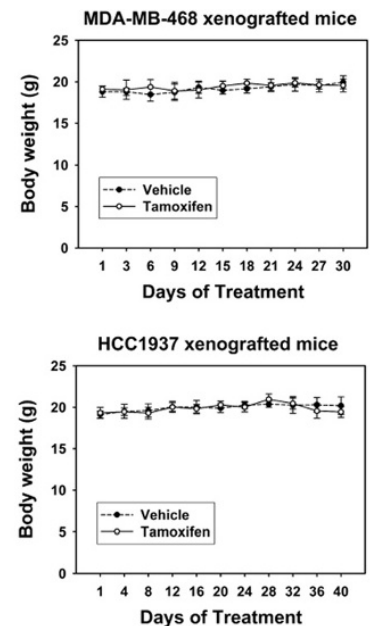

HCC 1937 tumors

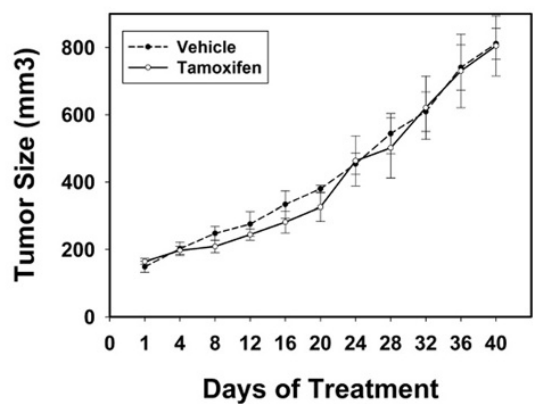

HCC 1937 tumors

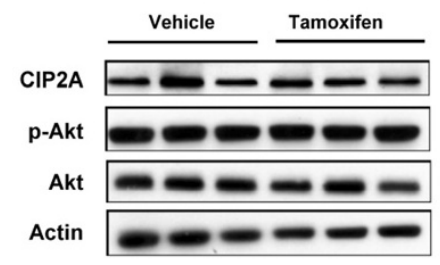

D

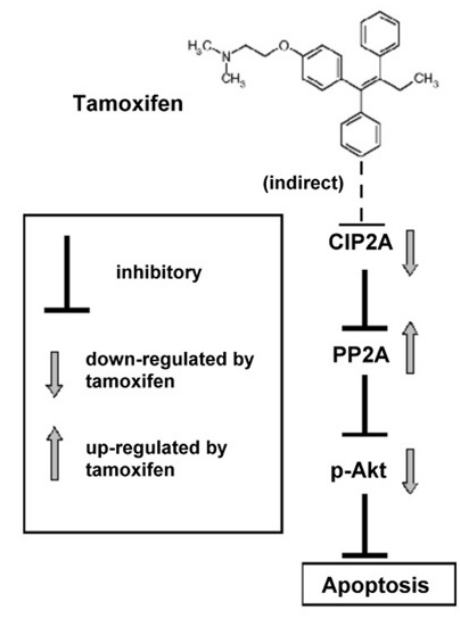

Figure 4 In vivo effect of tamoxifen on human breast cancer cell lines in xenograft nude mice. (A) Tamoxifen treatment decreased the size of MDA-MB-468 tumors (left) but did not affect HCC-1937 tumor cell growth (right). Points, mean values $(n=6)$; bars, SE; * $P<0.05$. Mice received either $100 \mathrm{mg} / \mathrm{kg}$ body weight tamoxifen citrate administered orally three times weekly or vehicle (1× phosphate-buffered saline), as described in the Methods section. (B) Western blot analysis of the expression levels of cancerous inhibitor of protein phosphatase 2A (CIP2A), phospho-Akt (p-Akt) and Akt in MDA-MB-468 and HCC-1937 xenografts treated with control or tamoxifen. (C) Body weight of xenograft mice bearing MDA-MB-468 (top) and HCC-1937 (bottom) tumors. Points, mean values $(n=6)$; bars, SD. (D) Schema of the molecular mechanism of the action of tamoxifen on the CIP2A/ PP2A pathway. By inhibiting CIP2A, tamoxifen restores protein phosphatase 2A (PP2A) activity downregulating p-Akt and leading to subsequent cell apoptosis. 
MDA-MB-468 tumors, whereas no significant change was seen in the control (vehicle-treated) tumors (Figure 4B, left panel). In the HCC-1937 tumors, the expression of CIP2A and p-Akt were not affected in either the tamoxifen- or control-treated tumors (Figure 4B, right panel). At the end of the experiment, all the animals had tolerated the treatments quite well without observable signs of toxicity and had stable body weights throughout the whole treatment course (Figure 4C). A schema summarizing the molecular mechanism of tamoxifen in sensitive ER-negative breast cancer cells is presented in Figure 4D. Tamoxifen inhibited CIP2A, restored PP2A activity and led to p-Akt downregulation and cancer cell apoptosis (Figure 4D).

\section{Expression of CIP2A correlates with expression of} p-Akt in breast tumor tissue from patients with estrogen receptor-negative breast cancers

In four representative breast tumor tissues from patients with ER-negative breast cancers with varying degrees (negative, weak, moderate and strong staining) of CIP2A expression, immunohistochemical staining for p-Akt showed that the intensity of nuclear expression for $\mathrm{p}$ Akt correlated with cytoplasmic staining for CIP2A (Figures 5A to 5D). Our previous data showed that 50 (87.7\%) of 57 tumor samples from triple-negative breast cancer patients demonstrated variable CIP2A expression levels [25]. A recent immunohistochemistry-based study demonstrated that CIP2A signature clustered with basaltype and HER2-positive breast cancer signatures and suggested that CIP2A is linked to these two subtypes of breast cancer [36]. To study the clinical significance of CIP2A, we further examined CIP2A and p-Akt expression in tumor samples from 123 patients with ER-negative breast cancers (including 53 (43.1\%) with HER2-positive breast cancers). As shown in Table 1, 96.7\% of patients had variable CIP2A expression levels (from low to high). High expression of CIP2A was significantly correlated with the patient's clinical stage at diagnosis, as well as with pathological microvascular invasion, but it was not significantly associated with age or HER2 status (Table 2). Survival analysis showed that patients with high CIP2A expression had worse progression-free survival as compared with patients with moderate to low or negative CIP2A expression (Table 2, Figure 5E). Moreover, moderate to high CIP2A expression correlated with high p-Akt expression in these tumor samples (Figure $5 \mathrm{E}$ ). The in vivo result, therefore, supported the correlation of CIP2A and p-Akt signaling found in vitro.

\section{Discussion}

In this study, we demonstrate the mechanism of action of the drug tamoxifen in ER-negative breast cancer cells, that is, induction of cancer cell apoptosis through

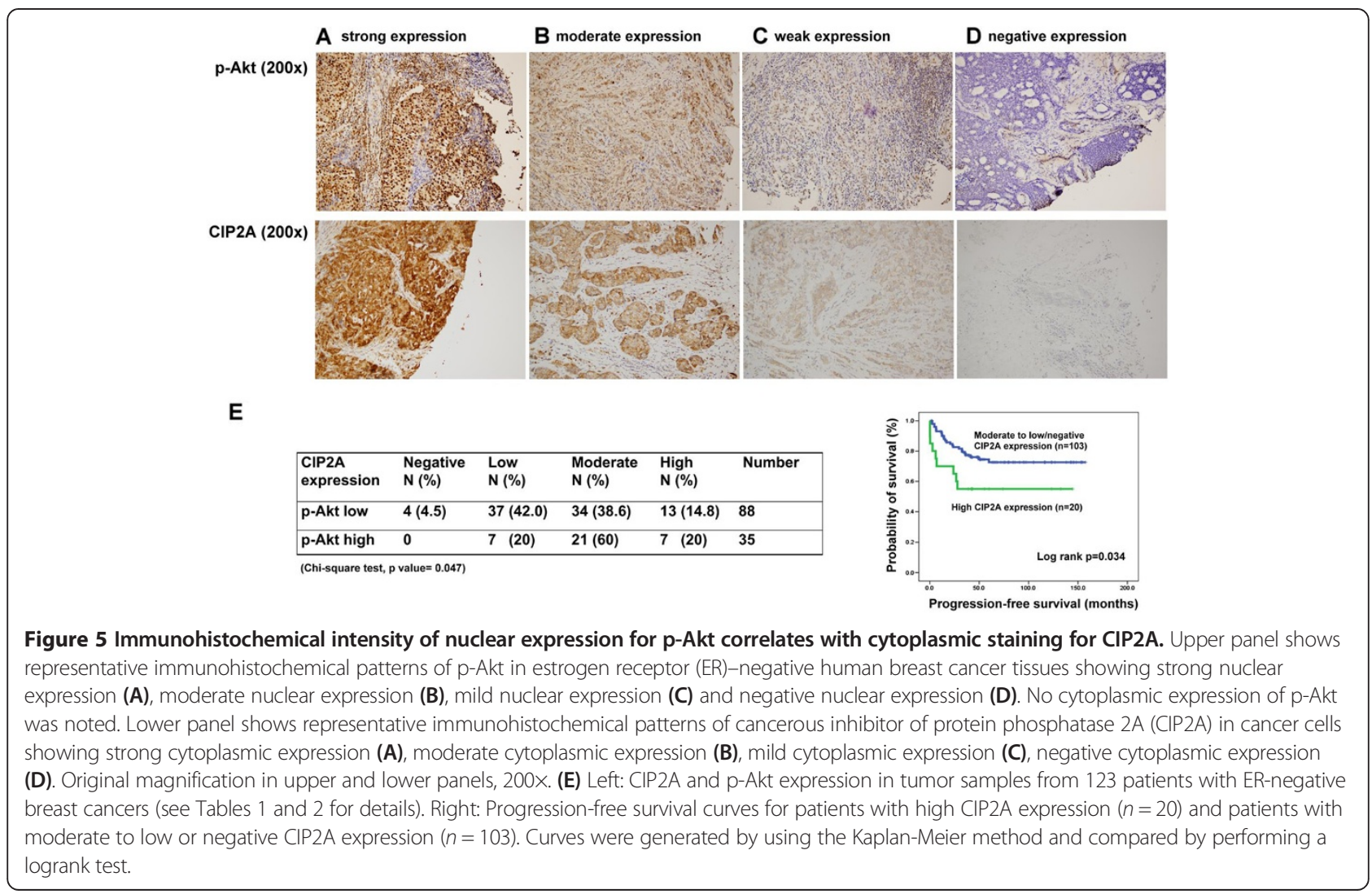


Table 1 General characteristics of primary tumor samples from 123 patients with hormone receptor-negative breast cancers $^{\mathrm{a}}$

\begin{tabular}{lll}
\hline Characteristic & $\mathbf{N}=\mathbf{1 2 3}$ & \% \\
\hline Median age, yr (IQR) & 54 (48 to 66) & \\
Tumor stage & 32 & 26.0 \\
T1 & 79 & 64.2 \\
T2 & 7 & 5.7 \\
T3 & 4 & 3.3 \\
T4 & 1 & 0.8 \\
Node-positive disease & 57 & 47.3 \\
Metastatic disease & 6 & 4.9 \\
TNM stage & & \\
I & 19 & 15.4 \\
II & 70 & 56.9 \\
III & 28 & 22.8 \\
IV & 6 & 4.9 \\
HER2-positive & & 43.1 \\
CIP2A expression & 53 & \\
Negative & & 3.3 \\
Low & 4 & 35.8 \\
Moderate & 44.7 \\
High & 55 & 16.3 \\
Positive p-Akt expression & 20 & 97.6 \\
\hline
\end{tabular}

${ }^{a}$ CIP2A, Cancerous inhibitor of protein phosphatase 2A HER2, Human

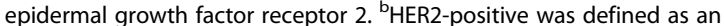
immunohistochemical staining score of $3+$ or $2+$ with gene amplification shown by fluorescence in situ hybridization.

CIP2A-dependent p-Akt downregulation. These findings not only increase current understanding of the drug mechanisms of tamoxifen but also support the rationale of targeting CIP2A in future drug development for ER-negative breast cancer.

Table 2 Clinicopathological characteristics according to CIP2A expression ${ }^{a}$

\begin{tabular}{llll}
\hline Characteristic & $\begin{array}{l}\text { Moderate to low } \\
\text { CIP2A expression, }\end{array}$ & $\begin{array}{l}\text { High CIP2A } \\
\text { expression, }\end{array}$ & P-value \\
& $\boldsymbol{n = 1 0 3}$ (\%) & $\boldsymbol{n = 2 0}(\%)$ & \\
\hline Median age (IQR) & $55(49.0$ to 67.0) & $\begin{array}{l}49(40.75 \text { to } \\
55.50)\end{array}$ & 0.401 \\
Advanced clinical stage & $23(22.3)$ & $11(55.0)$ & 0.011 \\
(stages III and IV) & & $9(45.0)$ & 0.001 \\
Microvascular invasion & $23(22.3)$ & $6(30.0)$ & 0.337 \\
HER2-positive & $47(45.6)$ & $12(60.0)$ & 0.338 \\
High p-Akt expression & $49(47.6)$ & $55 \%$ & 0.034 \\
\hline 5-year PFS & $76.7 \%$ &
\end{tabular}

${ }^{a} \mathrm{CIP} 2 \mathrm{~A}$, Cancerous inhibitor of protein phosphatase 2A; HER2, Human epidermal growth factor receptor 2; PFS, Progression-free survival. ${ }^{\text {bHER2-positive was }}$ defined as an immunohistochemical staining score of $3+$ or $2+$ with gene amplification shown by fluorescence in situ hybridization. 'Median follow-up period 50.5 months (IQR $=34.1$ to 86.8 ).
Our data clearly show an "off-ER $\alpha$ " effect of tamoxifen (Figure 1 and Additional file 1: Figures S1 and S2). In addition, we checked the expression of ER $\beta$ in MCF-7 and ER $\alpha$-negative cells (Additional file 1: Figure S3). Indeed, these cells showed positive ER $\beta$ expression. ER $\beta$, a second estrogen receptor, has been found to be expressed in $50 \%$ to $90 \%$ of $E R \alpha$-negative breast cancers [33]. Although tamoxifen is believed to target ER $\alpha$ in ER-positive breast cancers, this mixed agonist-antagonist can also transactivate ER $\beta$, raising the question whether ER $\beta$ has a prognostic value for tamoxifen responsiveness/ resistance [37]. Clinical studies have shown ER $\beta$ expression to be a good prognostic marker for tamoxifen responsiveness in both ER-positive and ER-negative breast cancer patients [33,37-39]. In vitro studies have suggested a tumor-suppressive role of ER $\beta$, particularly in ER-positive breast cancer cells $[33,37]$. Whether ER $\beta$ has multiple distinct roles in ER $\alpha$-negative breast cancers needs further investigation. It would be interesting to see whether ER $\beta$ plays a role in tamoxifen-induced effects on CIP2A/PP2A/p-Akt mechanisms, which requires more studies.

There is a growing body of evidence supporting the use of CIP2A as an anticancer target [16-20,23-25,40-43]. Accordingly, several agents that inhibit CIP2A have been identified, and some have demonstrated efficacy against different cancer cells. In our previous studies, we demonstrated that bortezomib, a proteasome inhibitor, induced apoptosis via proteasome-independent inhibition of CIP2A in triple-negative breast cancer cells [25], hepatocellular carcinoma cells [44], leukemia cells [24] and head and neck cancer cells [41]. Interestingly, erlotinib, as well as its derivatives, could also promote cancer cell death by affecting the same signaling pathway (CIP2A/ $\mathrm{PP} 2 \mathrm{~A} / \mathrm{p}$-Akt) $[42,45]$. In this study, we found that tamoxifen, a selective estrogen antagonist, induced significant cancer cell apoptosis in ER-negative breast cancer cells (Figure 1B). We confirmed the role of the CIP2A/PP2A/ p-Akt signaling pathway in tamoxifen-induced apoptosis in ER-negative breast cancer cells. Liang et al. found that rabdocoetsin B, an herbal extract of Rabdosia coetsa, also inhibited proliferation and induced apoptosis in lung cancer cells through CIP2A-dependent p-Akt downregulation [43]. Recently, Jung et al. found that a tumorsuppressive microRNA, miR-375, could suppress CIP2A and CIP2A-dependent Myc protein levels in oral cancer cells that resulted in inhibition of cancer cell proliferation, migration and invasion [46]. Furthermore, Sung et al. showed that when expression of CIP2A in tumor cells was induced by IL-10, the aggressiveness of pulmonary adenocarcinoma was aggravated [47]. We conclude from current evidence that CIP2A is an important molecule associated with cancer cell survival and could be a potential anticancer target in many malignant diseases. 
It is noteworthy, however, that depletion of CIP2A alone did not induce significant apoptosis in tamoxifenresistant HCC-1937 cells (Figure 2F). Similarly, CIP2A siRNA alone did not induce significant apoptosis in tamoxifen-sensitive MDA-MB-468 cells (Additional file 1: Figure S5). In a previous study, Come et al. [17] showed that CIP2A siRNA alone decreased the proliferation of MDA-MB-231 cells and inhibited the growth of xenograft MDA-MB-231 cells in vivo. However, Junttila et al. [16] and Côme et al. [17] showed that CIP2A siRNA alone does not induce significant apoptosis, but significantly inhibits cell proliferation. Consistent with previous studies, our data show depletion CIP2A per se is insufficient to induce apoptosis, but plays a key role in mediating apoptosis induced by several "CIP2A-ablating agents," including tamoxifen $[25,42,44,45,48]$. These results suggest CIP2A is essential but not sufficient in mediating tamoxifeninduced apoptosis. Alternatively, it can be argued that CIP2A downregulation per se may also participate in the apoptosis mechanism. We further tested the effects of common chemotherapeutic agents for breast cancers, including 5-FU, paclitaxel and docetaxel, compared with tamoxifen in MDA-MB-468 cells (Additional file 1: Figure S6). Interestingly, only tamoxifen induced significant CIP2A reduction, whereas all these agents induced apoptosis in MDA-MB-468 cells. More studies are needed to elucidate whether and at which steps CIP2A downregulation participates in the process of apoptosis.

Although most clinical evidence suggests that tamoxifen is particularly effective for ER-positive breast cancer because it acts by competitive inhibition of ER and estrogen-regulated genes, which slows tumor progression $[26,49]$, a $10 \%$ to $15 \%$ response rate has been reported in patients with ER-negative breast cancer [26]. Tamoxifen has also been shown to provide some protection in patients with ER-negative DCIS after resection [50,51]. Researchers in some other studies have proposed the ER-independent therapeutic potential of tamoxifen, including in antiangiogenesis [29], induction of mitochondrial dysfunction [30] and activation of Hsp90 [31], but none of these studies were conducted in breast cancer cells. Moreover, we performed coimmunoprecipitation experiments with CIP2A and Hsp90 in tamoxifen-treated MDA-MB-468 cells and found no apparent interactions between these two molecules upon tamoxifen treatment (Additional file 1: Figure S7). In contrast with previous studies, in our present study we explored the mechanism of tamoxifen using ER-negative breast cancer cell lines and identified a new mechanism of action of tamoxifen, namely, CIP2A-dependent p-Akt inhibition. Our results may partly explain why some ER-negative breast cancer patients respond to tamoxifen $[8,26,28]$. Future studies correlating response to tamoxifen with downregulation and/or pretreatment expression levels of CIP2A in breast cancer patients may help to establish a clinical role for CIP2A as a predictive factor in breast cancer. Furthermore, in our previous studies, we showed that bortezomib, by inhibiting the CIP2A/PP2A/p-Akt pathway, could sensitize hepatocellular carcinoma cells to an antihuman death receptor 5 antibody, CS-1008 [48], and could enhance radiation-induced apoptosis in cervical cancer and hepatocellular carcinoma cells [52]. Therefore, the potential application of the new CIP2A inhibitory mechanism of tamoxifen as part of a combination treatment strategy with other anti-breast cancer agents is worth further investigation.

In addition, we checked the effects of tamoxifen on cMyc and Bcl-2 in tamoxifen-sensitive cells to see if tamoxifen-induced CIP2A inhibition could also affect cell survival through dysregulation of other PP2A substrates that are involved in apoptosis (Additional file 1: Figure S8). Interestingly, tamoxifen showed differential effects on $\mathrm{c}-\mathrm{Myc}$ and Bcl-2 in sensitive cell lines (MDAMB-468, MDA-MB-231, MDA-MD-453 and SK-BR3). Tamoxifen reduced c-Myc expression more prominently in SK-BR3 cells and reduced Bcl-2 expression more prominently in MDA-MB-231 cells. Compared to the effects of tamoxifen on $\mathrm{p}$-Akt reduction, the $\mathrm{p}$-Akt downregulation was more consistent in sensitive cells and correlated better with tamoxifen-induced apoptosis (Figure 1).

In the present study, we show that tamoxifen suppressed CIP2A transcription, but did not affect the degradation of CIP2A protein after treatment with cycloheximide (Figure 3). These results suggest that tamoxifen affects CIP2A at the pretranscription level. To further decipher the possible mechanism of how tamoxifen affects CIP2A mRNA, we performed experiments with CIP2A promoter activity assay (Figure $3 \mathrm{C}$ ), ChIP assay (Figure 3D) and Western blotting for nuclear/cytoplasmic extracts (Figure 3E). The results suggest that tamoxifen may downregulate CIP2A transcription via affecting Elk1. Further mechanistic study is needed.

The present study has some limitations. Although we show here that ER $\alpha$-negative cells are sensitive to apoptosis induction by tamoxifen, it must be noted that the concentrations required to induce apoptosis in these cells is higher than for ER $\alpha$-positive cells. Our in vitro data showed at $5 \mu \mathrm{M}$ tamoxifen induced more apoptosis in ER $\alpha$-positive MCF-7 cells compared to that in ER $\alpha$ negative MDA-MB-453 cells (Additional file 1: Figure S2). A previous study by Salami et al. revealed a similar result in terms of apoptosis, in which MCF-7 cells responded to a lower tamoxifen concentration $(1 \mu \mathrm{M})$ in a comparison with MDA-MB468 cells, which were mainly affected at a higher dose $(20 \mu \mathrm{M})$ [53]. The usual effective dose of tamoxifen in humans is around 20 to $40 \mathrm{mg} /$ day [26,54]. Previous studies have shown a tumoristatic effect of tamoxifen on MCF-7 xenografted tumors in mice [55-58]. 
The effective doses of tamoxifen in these in vivo studies have been relatively low [55-58]. In addition, tamoxifen has been shown to affect cancer cell cycles at serum concentrations of tamoxifen achieved in breast cancer patients (about $1 \mu \mathrm{M}$ ) [55]. These data suggest that the doses of tamoxifen in ER $\alpha$-positive xenograft mice models could inhibit cell proliferation rather than directly kill cancer cells. The dose of tamoxifen $(100 \mathrm{mg} / \mathrm{kg}$ mouse body weight) used for xenografts of ER $\alpha$-negative cells (MDA-MB-468) in the present study is higher than that used for xenografts of MCF-7 cells previously reported in the literature. In a pharmacokinetic study, Robinson et al. showed that repeated large oral doses $(200 \mathrm{mg} / \mathrm{kg} /$ day for 6 days) of tamoxifen to athymic mice produced an array of serum metabolites similar to that seen in breast cancer patients [59]. Although our in vivo data show that tamoxifen inhibited tumor growth and downregulated protein levels of CIP2A in MDA-MB-468 xenograft tumors, we did not observe markers of apoptosis or proliferation and our results do not validate the role of CIP2A in tamoxifen-induced apoptosis in vivo. In this regard, more xenograft experiments using breast cancer cells with overexpression or downregulation of CIP2A and involving examination of apoptosis markers should be helpful.

Currently, the structural information of CIP2A is lacking, and the exact molecular mechanism of PP2A inhibition by CIP2A remains unclear; therefore, directly targeting CIP2A is difficult. Our data show that forskolin, a PP2A activator, sensitized HCC-1937 cells to tamoxifen-induced apoptosis (Figure 2E and Additional file 1: Figure S4). Recent studies have shown that pharmacologic restoration of PP2A tumor suppressor activity by PP2A-activating drugs (PADs; for example, forskolin, FTY720) effectively antagonizes cancer development and progression [60]. Accordingly, Perrotti et al. suggested the importance of PP2A as a druggable tumor suppressor in light of the possible use of PADs as anticancer agents [60].

\section{Conclusions}

We report that tamoxifen acts through CIP2A-dependent downregulation of p-Akt-mediated, tamoxifen-induced apoptosis in ER-negative breast cancer cells. Our results support the potential of CIP2A as a therapeutic target in breast cancer treatment. Further studies designed to unravel the detailed molecular modification of CIP2A by tamoxifen and its application in other cancer cell types are warranted.

\section{Additional file}

Additional file 1: Figure S1. Effect of tamoxifen in MCF-7 cells. Cells were exposed to tamoxifen at the indicated doses for 36 hours. Figure S2. Effects of tamoxifen and fulvestrant on ERa and CIP2A. Cells were treated with these agents at indicated doses for 36 hours. Fulvestrant was purchased from Sigma-Aldrich (St Louis, MO, USA). Figure S3. Expression of ERß in MCF-7 and ERa-negative breast cancer cells. Figure S4. Cotreatment of tamoxifen with forskolin enhanced PP2A activity in resistant HCC-1937 cells. Cells were treated with DMSO or tamoxifen $(7.5 \mu \mathrm{M})$ or cotreated with tamoxifen $(7.5 \mu \mathrm{M})$ and forskolin $(40 \mu \mathrm{M})$ for 36 hours. Columns, mean values $(n=3)$; bars, SD; ${ }^{*} P<0.05$. Figure S5. Downregulation of CIP2A by siRNA increased tamoxifen-induced apoptosis in MDA-MB-468 cells. Cells were transfected with either scrambled or CIP2A siRNA for 72 hours, followed by exposure to tamoxifen for 36 hours. Columns, mean values $(n=3)$; bars, SD; ${ }^{*} P<0.05$. Figure S6. Effects of tamoxifen and common chemotherapeutic agents on apoptosis associated with CIP2A expression. Cells were treated with DMSO, tamoxifen $(5 \mu \mathrm{M}), 5-\mathrm{FU}(40 \mu \mathrm{M})$, paclitaxel (20 nM) or docetaxel $(2 \mu \mathrm{M})$ for 36 hours and assayed for CIP2A and apoptosis. Figure S7. Coimmunoprecipitation of CIP2A and Hsp90 in MDA-MB-468 cells treated with or without tamoxifen for 36 hours. Figure S8. Effects of tamoxifen on C-Myc and $\mathrm{BCl}-2$ expressions in tamoxifen-sensitive ERa-negative breast cancer cells. Cells were treated with DMSO or tamoxifen for 36 hours.

\section{Abbreviations}

CIP2A: Cancerous inhibitor of protein phosphatase 2A; DMSO: Dimethyl sulfoxide; ER: Estrogen receptor; HER2: Human epidermal growth factor receptor type 2; Hsp: Heat shock protein; PARP: Poly(ADP-ribose) polymerase; PP2A: Protein phosphatase 2A; siRNA: Small interfering RNA.

\section{Competing interests}

The authors declare that they have no competing interests.

\section{Authors' contributions}

LMT and KFC were responsible for coordination and manuscript editing as well as acting as corresponding authors. CYL drafted the manuscript. CYL, $\mathrm{MHH}, \mathrm{DSW}, \mathrm{PYC}, \mathrm{JCS}, \mathrm{THT}, \mathrm{CTH}, \mathrm{TTC}$, and CYW conducted in vitro experiments. CYL, MHH, DSW, PYC, JCS, THT, and CTH conducted animal and histopathological experiments. CYL, MHH, CTH, TTC, CYW, LMT, and KFC performed or helped clinical data acquisition and analysis. CWS, LMT, and KFC helped in data interpretation and statistical analysis. CYL, MHH, DSW, PYC, JCS, THT, CTH, TTC, CYW and CWS prepared the figures. All authors had substantial contributions to the conception or design of the work. All authors read the final manuscript, revised it critically for intellectual content and approved the final manuscript. All authors agreed with the accuracy and integrity of all parts of the work.

\section{Acknowledgements}

This research was supported by grants from the Taiwan Clinical Oncology Research Foundation and from Yen Tjing Ling Medical Foundation (Cl-10210); 101XDAA00105 from Department of Health, Taipei City Hospital, Taiwan; 103-2325-B-075-002 and 102-2325-B-075-003 from the Ministry of Science and Technology, Taiwan; V102A-005, V101B-003, V102B-011 and V103C-141 from Taipei Veterans General Hospital; TVGH-NTUH Joint Research Program VN103-08 from Taipei Veterans General Hospital and National Taiwan University Hospital; and MOHW103-TD-B-111-02 from the Center of Excellence for Cancer Research at Taipei Veterans General, the Ministry of Health and Welfare, Executive Yuan, Taiwan.

\section{Author details}

${ }^{1}$ Division of Hematology and Oncology, Department of Medicine, Taipei Veterans General Hospital, No. 201, Sec. 2, Shih-Pai Road, Taipei 112, Taiwan. ${ }^{2}$ School of Medicine, National Yang-Ming University, No. 155, Sec. 2, Li-Nong Street, Taipei 112, Taiwan. ${ }^{3}$ Department of Surgery, Taipei Veterans General Hospital, No. 201, Sec. 2, Shih-Pai Road, Taipei 112, Taiwan. ${ }^{4}$ Institute of Biopharmaceutical Sciences, National Yang-Ming University, No. 155 Sec. 2, Li-Nong Street, Taipei 112, Taiwan. ${ }^{5}$ Department of Pathology, St Martin De Porres Hospital, No. 565, Sec. 2, Daya Road, Chiayi 600, Taiwan. ${ }^{6}$ Department of Medical Research, National Taiwan University Hospital, No. 7, Chung-Shan South Road, Taipei 100, Taiwan. ${ }^{7}$ National Center of Excellence for Clinical Trial and Research, National Taiwan University Hospital, No. 7, Chung-Shan South Road, Taipei 100, Taiwan. ${ }^{8}$ Program in Molecular Medicine, School of Life Sciences, National Yang-Ming University, No. 155, Sec. 2, Li-Nong Street, Taipei 112, Taiwan. ${ }^{9}$ Department of Biological Science and Technology, National Chiao Tung University, No. 1001, University Road, Hsinchu 300, 
Taiwan. ${ }^{10}$ Department of Pathology, Taichung Hospital, Ministry of Health and Welfare, No. 199, Sec. 1, San-Min Road, Taichung 403, Taiwan. "'Division of Hematology \& Oncology, Department of Medicine, Yang-Ming Branch of Taipei City Hospital, No. 105, Yusheng Street, Taipei 112, Taiwan. ${ }^{12}$ Medical Research Center, Cardinal Tien Hospital, School of Medicine, Fu Jen Catholic University, No. 362, Zhongzheng Road, New Taipei City 231, Taiwan. ${ }^{13}$ Department of Internal Medicine, Cardinal Tien Hospital, School of Medicine, Fu Jen Catholic University, No. 362, Zhongzheng Road, New Taipei City 231, Taiwan

Received: 1 October 2013 Accepted: 21 August 2014

Published online: 17 September 2014

\section{References}

1. Sørlie T, Perou CM, Tibshirani R, Aas T, Geisler S, Johnsen H, Hastie T, Eisen MB, van de Rijn M, Jeffrey SS, Thorsen T, Quist H, Matese JC, Brown PO, Botstein D, Lønning $P E$, Børresen-Dale AL: Gene expression patterns of breast carcinomas distinguish tumor subclasses with clinical implications. Proc Natl Acad Sci U S A 2001, 98:10869-10874

2. Rouzier R, Perou CM, Symmans WF, Ibrahim N, Cristofanilli M, Anderson K, Hess KR, Stec J, Ayers M, Wagner P, Morandi P, Fan C, Rabiul I, Ross JS, Hortobagyi GN, Pusztai L: Breast cancer molecular subtypes respond differently to preoperative chemotherapy. Clin Cancer Res 2005, 11:5678-5685.

3. Perou CM, Sørlie T, Eisen MB, van de Rijn M, Jeffrey SS, Rees CA, Pollack JR, Ross DT, Johnsen H, Akslen LA, Fluge O, Pergamenschikov A, Williams C, Zhu SX, Lønning PE, Børresen-Dale AL, Brown PO, Botstein D: Molecular portraits of human breast tumours. Nature 2000, 406:747-752.

4. Nguyen PL, Taghian AG, Katz MS, Niemierko A, Abi Raad RF, Boon WL, Bellon JR, Wong JS, Smith BL, Harris JR: Breast cancer subtype approximated by estrogen receptor, progesterone receptor, and HER-2 is associated with local and distant recurrence after breast-conserving therapy. J Clin Oncol 2008, 26:2373-2378.

5. Huang CS, Lin CH, Lu YS, Shen CY: Unique features of breast cancer in Asian women-breast cancer in Taiwan as an example. J Steroid Biochem Mol Biol 2010, 118:300-303.

6. Kennecke H, Yerushalmi R, Woods R, Cheang MC, Voduc D, Speers $\mathrm{CH}$, Nielsen TO, Gelmon K: Metastatic behavior of breast cancer subtypes. J Clin Oncol 2010, 28:3271-3277.

7. Cardoso F, Loibl S, Pagani O, Graziottin A, Panizza P, Martincich L, Gentilini O, Peccatori F, Fourquet A, Delaloge S, Marotti L, Penault-Llorca F, Kotti-Kitromilidou AM, Rodger A, Harbeck N: The European Society of Breast Cancer Specialists recommendations for the management of young women with breast cancer. Eur J Cancer 2012, 48:3355-3377.

8. Theriault RL, Carlson RW, Allred C, Anderson BO, Burstein HJ, Edge SB, Farrar WB, Forero A, Giordano SH, Goldstein LJ, Gradishar WJ, Hayes DF, Hudis CA, Isakoff SJ, Ljung BME, Mankoff DA, Marcom PK, Mayer IA, McCormick B, Pierce LJ, Reed EC, Schwartzberg LS, Smith ML, Soliman H, Somlo G, Ward $J H$, Wolff AC, Zellars R, Shead DA, Kumar R, National Comprehensive Cancer Network: Breast cancer, version 3.2013: featured updates to the NCCN guidelines. J Natl Compr Canc Netw 2013, 11:753-760.

9. Mumby M: PP2A: unveiling a reluctant tumor suppressor. Cell 2007, 130:21-24.

10. Switzer CH, Ridnour LA, Cheng RY, Sparatore A, Del Soldato P, Moody TW, Vitek MP, Roberts DD, Wink DA: Dithiolethione compounds inhibit Akt signaling in human breast and lung cancer cells by increasing PP2A activity. Oncogene 2009, 28:3837-3846.

11. Seshacharyulu P, Pandey P, Datta K, Batra SK: Phosphatase: PP2A structural importance, regulation and its aberrant expression in cancer. Cancer Lett 2013, 335:9-18

12. Janssens V, Goris J: Protein phosphatase $2 \mathrm{~A}$ : a highly regulated family of serine/threonine phosphatases implicated in cell growth and signalling. Biochem J 2001, 353:417-439.

13. Rangarajan A, Hong SJ, Gifford A, Weinberg RA: Species- and cell type-specific requirements for cellular transformation. Cancer Cell 2004, 6:171-183. A published erratum appears in Cancer Cell 2013, 24:394-398.

14. Chen KF, Yeh PY, Hsu C, Hsu CH, Lu YS, Hsieh HP, Chen PJ, Cheng AL: Bortezomib overcomes tumor necrosis factor-related apoptosis-inducing ligand resistance in hepatocellular carcinoma cells in part through the inhibition of the phosphatidylinositol 3-kinase/Akt pathway. J Biol Chem 2009, 284:11121-11133.

15. Sablina AA, Chen W, Arroyo JD, Corral L, Hector M, Bulmer SE, DeCaprio JA, Hahn WC: The tumor suppressor PP2A A 3 regulates the RalA GTPase. Cell 2007, 129:969-982.
16. Junttila MR, Puustinen $P$, Niemelä M, Ahola R, Arnold H, Böttzauw T, Ala-aho R, Nielsen C, Ivaska J, Taya Y, Lu SL, Lin S, Chan EK, Wang XJ, Grènman R, Kast J, Kallunki T, Sears R, Kähäri VM, Westermarck J: CIP2A inhibits PP2A in human malignancies. Cell 2007, 130:51-62.

17. Côme C, Laine A, Chanrion M, Edgren H, Mattila E, Liu X, Jonkers J, Ivaska J, Isola J, Darbon JM, Kallioniemi O, Thézenas S, Westermarck J: CIP2A is associated with human breast cancer aggressivity. Clin Cancer Res 2009, 15:5092-5100.

18. Dong QZ, Wang Y, Dong XJ, Li ZX, Tang ZP, Cui QZ, Wang EH: CIP2A is overexpressed in non-small cell lung cancer and correlates with poor prognosis. Ann Surg Oncol 2011, 18:857-865.

19. Fang $Y$, Li Z, Wang $X$, Zhang S: CIP2A is overexpressed in human ovarian cancer and regulates cell proliferation and apoptosis. Tumour Biol 2012, 33:2299-2306.

20. Li W, Ge Z, Liu C, Liu Z, Bjorkholm M, Jia J, Xu D: CIP2A is overexpressed in gastric cancer and its depletion leads to impaired clonogenicity, senescence, or differentiation of tumor cells. Clin Cancer Res 2008, 14:3722-3728

21. Vaarala MH, Väisänen MR, Ristimäki A: CIP2A expression is increased in prostate cancer. J Exp Clin Cancer Res 2010, 29:136.

22. Wang J, Li W, Li L, Yu X, Jia J, Chen C: CIP2A is over-expressed in acute myeloid leukaemia and associated with HL60 cells proliferation and differentiation. Int I Lab Hematol 2011, 33:290-298.

23. Choi YA, Park JS, Park MY, Oh KS, Lee MS, Lim JS, Kim Kl, Kim KY, Kwon J, Yoon DY, Moon EY, Yang Y: Increase in CIP2A expression is associated with doxorubicin resistance. FEBS Lett 2011, 585:755-760.

24. Liu CY, Shiau CW, Kuo HY, Huang HP, Chen MH, Tzeng CH, Chen KF: Cancerous inhibitor of protein phosphatase $2 \mathrm{~A}$ determines bortezomibinduced apoptosis in leukemia cells. Haematologica 2013, 98:729-738.

25. Tseng LM, Liu CY, Chang KC, Chu PY, Shiau CW, Chen KF: CIP2A is a target of bortezomib in human triple negative breast cancer cells. Breast Cancer Res 2012, 14:R68.

26. Osborne CK: Tamoxifen in the treatment of breast cancer. N Engl J Med 1998, 339:1609-1618.

27. Early Breast Cancer Trialists' Collaborative Group (EBCTCG): Effects of chemotherapy and hormonal therapy for early breast cancer on recurrence and 15-year survival: an overview of the randomised trials. Lancet 2005, 365:1687-1717.

28. Osborne CK, Yochmowitz MG, Knight WA 3rd, McGuire WL: The value of estrogen and progesterone receptors in the treatment of breast cancer. Cancer 1980, 46(12 Suppl):2884-2888.

29. Blackwell KL, Haroon ZA, Shan S, Saito W, Broadwater G, Greenberg CS, Dewhirst MW: Tamoxifen inhibits angiogenesis in estrogen receptor-negative animal models. Clin Cancer Res 2000, 6:4359-4364.

30. Obrero M, Yu DV, Shapiro DJ: Estrogen receptor-dependent and estrogen receptor-independent pathways for tamoxifen and 4-hydroxytamoxifen-induced programmed cell death. J Biol Chem 2002, 277:45695-45703.

31. Zhao R, Leung E, Grüner S, Schapira M, Houry WA: Tamoxifen enhances the Hsp90 molecular chaperone ATPase activity. PLoS One 2010, 5:e9934.

32. Yeh WL, Shioda K, Coser KR, Rivizzigno D, McSweeney KR, Shioda T: Fulvestrant-induced cell death and proteasomal degradation of estrogen receptor a protein in MCF-7 cells require the CSK c-Src tyrosine kinase. PLoS One 2013, 8:e60889.

33. Shanle EK, Zhao Z, Hawse J, Wisinski K, Keles S, Yuan M, Xu W: Research resource: global identification of estrogen receptor $\beta$ target genes in triple negative breast cancer cells. Mol Endocrinol 2013, 27:1762-1775.

34. Khanna A, Okkeri J, Bilgen T, Tiirikka T, Vihinen M, Visakorpi T, Westermarck J: ETS1 mediates MEK1/2-dependent overexpression of cancerous inhibitor of protein phosphatase 2A (CIP2A) in human cancer cells. PLoS One 2011, 6:e17979.

35. Pallai R, Bhaskar A, Sodi V, Rice LM: Ets1 and Elk1 transcription factors regulate cancerous inhibitor of protein phosphatase $2 \mathrm{~A}$ expression in cervical and endometrial carcinoma cells. Transcription 2012, 3:323-335.

36. Niemelä M, Kauko O, Sihto H, Mpindi JP, Nicorici D, Pernila P, Kallioniemi OP, Joensuu H, Hautaniemi S, Westermarck J: CIP2A signature reveals the MYC dependency of CIP2A-regulated phenotypes and its clinical association with breast cancer subtypes. Oncogene 2012, 31:4266-4278.

37. Leung YK, Lee MT, Lam HM, Tarapore P, Ho SM: Estrogen receptor- $\beta$ and breast cancer: translating biology into clinical practice. Steroids 2012, 77:727-737. 
38. Gruvberger-Saal SK, Bendahl PO, Saal LH, Laakso M, Hegardt C, Edén P, Peterson C, Malmström P, Isola J, Borg A, Fernö M: Estrogen receptor $\beta$ expression is associated with tamoxifen response in ERa-negative breast carcinoma. Clin Cancer Res 2007, 13:1987-1994.

39. Honma N, Horii R, Iwase T, Saji S, Younes M, Takubo K, Matsuura M, Ito Y, Akiyama F, Sakamoto G: Clinical importance of estrogen receptor- $\beta$ evaluation in breast cancer patients treated with adjuvant tamoxifen therapy. J Clin Oncol 2008, 26:3727-3734.

40. Xue Y, Wu G, Wang X, Zou X, Zhang G, Xiao R, Yuan Y, Long D, Yang J, Wu Y, $X u H$, Liu F, Liu M: CIP2A is a predictor of survival and a novel therapeutic target in bladder urothelial cell carcinoma. Med Oncol 2013, 30:406.

41. Lin YC, Chen KC, Chen CC, Cheng AL, Chen KF: CIP2A-mediated Akt activation plays a role in bortezomib-induced apoptosis in head and neck squamous cell carcinoma cells. Oral Oncol 2012, 48:585-593.

42. Yu HC, Chen HJ, Chang YL, Liu CY, Shiau CW, Cheng AL, Chen KF: Inhibition of CIP2A determines erlotinib-induced apoptosis in hepatocellular carcinoma. Biochem Pharmacol 2013, 85:356-366.

43. Ma L, Wen ZS, Liu Z, Hu Z, Ma J, Chen XQ, Liu YQ, Pu JX, Xiao WL, Sun HD, Zhou GB: Overexpression and small molecule-triggered downregulation of CIP2A in lung cancer. PLoS One 2011, 6:e20159.

44. Chen KF, Liu CY, Lin YC, Yu HC, Liu TH, Hou DR, Chen PJ, Cheng AL: CIP2A mediates effects of bortezomib on phospho-Akt and apoptosis in hepatocellular carcinoma cells. Oncogene 2010, 29:6257-6266.

45. Chen KF, Pao KC, Su JC, Chou YC, Liu CY, Chen HJ, Huang JW, Kim I, Shiau CW: Development of erlotinib derivatives as CIP2A-ablating agents independent of EGFR activity. Bioorg Med Chem 2012, 20:6144-6153.

46. Jung HM, Patel RS, Phillips BL, Wang H, Cohen DM, Reinhold WC, Chang LJ, Yang $L$, Chan EK: Tumor suppressor miR-375 regulates MYC expression via repression of CIP2A coding sequence through multiple miRNA-mRNA interactions. Mol Biol Cell 2013, 24:1638-1648.

47. Sung WW, Wang YC, Lin PL, Cheng YW, Chen CY, Wu TC, Lee H: IL-10 promotes tumor aggressiveness via upregulation of CIP2A transcription in lung adenocarcinoma. Clin Cancer Res 2013, 19:4092-4103.

48. Chen KF, Yu HC, Liu CY, Chen HJ, Chen YC, Hou DR, Chen PJ, Cheng AL: Bortezomib sensitizes HCC cells to CS-1008, an antihuman death receptor 5 antibody, through the inhibition of CIP2A. Mol Cancer Ther 2011, 10:892-901.

49. Carlson RW, Allred DC, Anderson BO, Burstein HJ, Edge SB, Farrar WB, Forero A, Giordano SH, Goldstein LJ, Gradishar WJ, Hayes DF, Hudis CA, Isakoff SJ, Ljung BM, Mankoff DA, Marcom PK, Mayer IA, McCormick B, Pierce LJ, Reed EC, Smith ML, Soliman H, Somlo G, Theriault RL, Ward JH, Wolff AC, Zellars R, Kumar R, Shead DA, National Comprehensive Cancer Network: Metastatic breast cancer, version 1.2012: featured updates to the NCCN guidelines. J Natl Compr Canc Netw 2012, 10:821-829.

50. Schmale I, Liu S, Rayhanabad J, Russell CA, Sener SF: Ductal carcinoma in situ (DCIS) of the breast: perspectives on biology and controversies in current management. J Surg Oncol 2012, 105:212-220.

51. Powles TJ, Ashley S, Tidy A, Smith IE, Dowsett M: Twenty-year follow-up of the Royal Marsden randomized, double-blinded tamoxifen breast cancer prevention trial. J Natl Cancer Inst 2007, 99:283-290.

52. Huang CY, Wei CC, Chen KC, Chen HJ, Cheng AL, Chen KF: Bortezomib enhances radiation-induced apoptosis in solid tumors by inhibiting CIP2A. Cancer Lett 2012, 317:9-15.

53. Salami S, Karami-Tehrani F: Biochemical studies of apoptosis induced by tamoxifen in estrogen receptor positive and negative breast cancer cell lines. Clin Biochem 2003, 36:247-253.

54. Pearson $\mathrm{OH}$, Manni A, Arafah BM: Antiestrogen treatment of breast cancer: an overview. Cancer Res 1982, 42(8 Suppl):3424s-3429s.

55. Osborne CK, Hobbs K, Clark GM: Effect of estrogens and antiestrogens on growth of human breast cancer cells in athymic nude mice. Cancer Res 1985, 45:584-590.

56. Gottardis MM, Robinson SP, Jordan VC: Estradiol-stimulated growth of MCF-7 tumors implanted in athymic mice: a model to study the tumoristatic action of tamoxifen. J Steroid Biochem 1988, 30:311-314

57. Gottardis MM, Robinson SP, Satyaswaroop PG, Jordan VC: Contrasting actions of tamoxifen on endometrial and breast tumor growth in the athymic mouse. Cancer Res 1988, 48:812-815.

58. lino $Y$, Wolf DM, Langan-Fahey SM, Johnson DA, Ricchio M, Thompson ME, Jordan VC: Reversible control of oestradiol-stimulated growth of MCF-7 tumours by tamoxifen in the athymic mouse. Br J Cancer 1991, 64:1019-1024.
59. Robinson SP, Langan-Fahey SM, Jordan VC: Implications of tamoxifen metabolism in the athymic mouse for the study of antitumor effects upon human breast cancer xenografts. Eur J Cancer Clin Oncol 1989, 25:1769-1776.

60. Perrotti D, Neviani P: Protein phosphatase 2A: a target for anticancer therapy. Lancet Oncol 2013, 14:e229-e238.

doi:10.1186/s13058-014-0431-9

Cite this article as: Liu et al:: Tamoxifen induces apoptosis through cancerous inhibitor of protein phosphatase 2A-dependent phospho-Akt inactivation in estrogen receptor-negative human breast cancer cells. Breast Cancer Research 2014 16:431.

\section{Submit your next manuscript to BioMed Central and take full advantage of:}

- Convenient online submission

- Thorough peer review

- No space constraints or color figure charges

- Immediate publication on acceptance

- Inclusion in PubMed, CAS, Scopus and Google Scholar

- Research which is freely available for redistribution

Submit your manuscript at www.biomedcentral.com/submit
C) Biomed Central 